\title{
O TRABALHO E A SAÚDE DO TRABALHADOR NA INDÚSTRIA DE CALÇADOS
}

Vera Lucia Navarro

Resumo: O texto debate a forma como as mudanças verificadas no processo e na organização do trabalho na indústria de calçados de Franca (SP) - que se intensificaram a partir dos anos 90, e resultaram no aumento do trabalho terceirizado, no trabalho em domicílio e na maior intensificação das atividades no interior das fábricas - repercutem na saúde dos trabalhadores daquele ramo industrial.

Palavras-chave: saúde do trabalhador; reestruturação produtiva; indústria de calçados.

Abstract: This article discusses how changes in the process and organization of the footwear industry in Franca, São Paulo State, have affected the health of this sector's workers. These changes came into force in 1990 and resulted in an increase in sub-contracting, home-based employment and the intensification of activity inside the factory.

Key words: workers' health; productive restructuring; footwear industry.

$\mathrm{U}$ ma das principais características do novo padrão de acumulação do capital tem sido a intensificação da exploração da força de trabalho, quer por meio da adoção de novas tecnologias, quer pela utilização de novas formas de organização da produção e do trabalho ou de mudanças nas próprias relações de trabalho que implicam contratos precários, na subcontratação, no trabalho a domicílio, no aumento desmedido da jornada de trabalho e, até mesmo, na exploração criminosa do trabalho infantil. A intensificação do trabalho, que cada vez mais se faz presente na contemporaneidade, tem ocasionado o aumento das doenças relacionadas ao trabalho e criado condições que conduzem ao incremento da probabilidade de acidentes causadores de incapacidade temporária permanente ou mesmo de mortes de trabalhadores, o que evidencia o vínculo causal entre saúde e trabalho.

Para que se possa apreender quais são as implicações para a saúde dos trabalhadores derivadas dessas mudanças, deve-se compreender a lógica que rege a intensificação do trabalho na contemporaneidade, que está associada às mudanças tecnológicas e organizacionais e ao processo de reestruturação produtiva que ocorre em escala global e que se intensifica, no Brasil, a partir da década de 90 .
Diante da complexidade do processo de reestruturação produtiva em curso no país, são necessários estudos empíricos que possam contribuir para sua elucidação, apesar da existência de uma significativa literatura já produzida. É necessário, ainda, ouvir dos próprios trabalhadores como essas mudanças afetam suas condições de trabalho e sua saúde. Este artigo baseia-se em estudos que se vêm realizando desde meados da década passada com trabalhadores da indústria de calçados de Franca (SP), ${ }^{1}$ que buscam fornecer elementos para compreensão de como vem-se dando a exploração da força de trabalho no país, no contexto da reestruturação produtiva, e quais as repercussões sobre a saúde dos trabalhadores, particularmente dos empregados na produção calçadista francana.

O debate acerca da superexploração da força de trabalho remete ao debate de algumas particularidades na forma de objetivação do capitalismo no Brasil. O processo de produção capitalista visa a valorização do capital. A condição histórica necessária para essa forma particular de produção social é a existência de indivíduos totalmente livres, até dos meios de produção - de proletários, em condições de vender sua força de trabalho em troca de um 
salário, única alternativa que lhes resta, para manter e reproduzir sua própria existência.

$\mathrm{Na}$ sociedade capitalista, tão diferente de outras formas sociais historicamente conhecidas, a valorização do capital tem como condição e premissa a produção social da mercadoria numa sociedade cujos membros competem e se opõem como pessoas, que só se contrapõem em sua qualidade de possuidores de mercadorias, e que apenas enquanto tais entram em contato umas com as outras (Marx, 1978:8).

O objetivo específico do capital é, então, a produção de trabalho excedente, a apropriação, no curso do processo de produção real - de trabalho não pago, que se objetiva como mais-valia. Nas palavras de Marx (1978:22-32), a mais-valia é o produto específico do processo de produção capitalista: “[...] O produto do processo de produção capitalista não é simplesmente produto (valor de uso), nem simples mercadoria, isto é, produto que tem valor de troca; seu produto específico é a mais-valia. [...] o processo de trabalho não é mais que um meio do processo de valorização, processo que por sua vez é essencialmente produção de mais-valia, isto é processo de objetivação de trabalho não pago".

No Brasil, em razão do caráter caudatário e subordinado da produção capitalista às economias centrais, a produção capitalista não objetiva a incorporação do excedente obtido apenas ao capital constituído nos limites das fronteiras nacionais, mas também, e talvez em montante mais significativo, ao capital internacionalmente constituído.

A voracidade com que o capital consome a força de trabalho no Brasil evidencia a intensidade desse processo de acumulação ou o grau de superexploração a que essa força de trabalho está submetida. ${ }^{2}$

$\mathrm{O}$ arrocho salarial, meio de ampliar a mais-valia - uma vez que reduz o montante equivalente ao tempo de trabalho socialmente necessário, ampliando o excedente-, sem a necessidade de alterar a jornada de trabalho ou incorporar qualquer inovação tecnológica à produção, vem coexistindo há décadas com outros meios de ampliação de trabalho excedente ou trabalho não pago.

No Brasil, tanto na produção industrial quanto na rural, ocorre a combinação das duas formas de extração de mais-valia, a absoluta e a relativa (Costa, 1981:106). Igualmente, coexistem a subordinação real com a subordinação formal do trabalho ao capital (Ianni, 1984:83-84 e Santos, 1984:125-133).

Essa situação, que poderia parecer paradoxal em uma sociedade capitalista industrializada - a redução real dos salários, a combinação de estratégias, meios, técnicas e relações de produção arcaicas com modernas -, a coexistência de relações de trabalho assalariado com a parceria, a meação, o trabalho domiciliar, etc., torna-se extremamente funcional, do ponto de vista das necessidades do processo de acumulação, de remunerar o capital tanto no país quanto no exterior. Esses meios de ampliação de maisvalia são imanentes à forma particular de desenvolvimento do capitalismo no país (Braverman, 1987:244).

As mudanças em curso no mercado de trabalho no Brasil apontam para a continuidade desses meios que o capital se vale para reproduzir-se ampliadamente, aumentando o grau de exploração da força de trabalho, já tão intenso no país. Como boa parte das pesquisas tem apontado, a terceirização do trabalho, que é parte do processo de reestruturação produtiva e que se intensificou a partir dos anos de 1990, é sinônimo, na maioria das vezes, de superexploração da força de trabalho.

Pesquisadores da questão da terceirização no Brasil têm destacado dois padrões distintos e contrastantes de adoção da terceirização. O primeiro considerado como um padrão 'reestruturante', 'autêntico', tem sido apontado como o que busca a redução de custos valendo-se de determinantes tecnológicos e organizacionais.

Segundo Faria (1994:43-44), essa modalidade de terceirização objetiva "alcançar tanto elementos de produtividade quanto condições novas de competitividade. É a imposição das tecnologias gerenciais de qualidade. É o outsourcing (a busca de suprimentos) total. A palavra de ordem é paternship (parceria) em todo o fluxo produtivo, nas relações para frente, com o mercado, para trás com os fornecedores e também com os empregados".

A adoção desse padrão de terceirização do ponto de vista empresarial "[...] significa focalizar a sua atividade naquilo que ela considera estratégico, sua atividade de excelência. Focalizar onde ela detém o domínio tecnológico e a capacidade de produzir com mais qualidade e custos menores. Assim, a empresa fragmenta a sua cadeia produtiva interna, transferindo para terceiros atividades de produção [...]. [...] A adoção da terceirização, dentro de uma estratégia reestruturante, possibilita que a empresa reduza a diversidade das formas de produção e dos processos de trabalho envolvidos, aumentando o controle sobre o processo de produção. A focalização, decorrente da terceirização, permite ganhos de racionalização, eficiência e produtividade. Por outro lado, alguns riscos, relacionados à instabilidade do mercado e à ausência de um crescimento sustentado na demanda, são transferidos para 
terceiros. Esses aspectos que caracterizam o padrão reestruturante de terceirização são todos relacionados com a questão da qualidade e produtividade, sendo, portanto, elementos constitutivos da atual mudança de paradigma tecnológico" (Dieese, 1994:34-35).

No entanto, o que predomina no país é um segundo padrão de terceirização, referenciado como "fraudulento", "espúrio" ou "predatório", que busca a redução de custos mediante exploração de relações precárias de trabalho e que, para tanto, recorre à utilização de subcontratação de mãode-obra, aos contratos temporários de trabalho, ao trabalho em domicílio, ao trabalho em tempo parcial e ao trabalho sem registro em carteira. Essas táticas podem e vêm sendo empregadas tanto isoladas como conjuntamente e, o que se observa, "[...] é uma flexibilização de direitos trabalhistas, um mecanismo de tentar neutralizar a regulação estatal e a regulação sindical" (Dieese, 1994:34-35). Alves (1996:144145) afirma que, no Brasil "[...] a terceirização se dá à custa da intensidade maior do trabalho e da manutenção da estrutura de poder, com poucas mudanças na hierarquia (mantendo, portanto, o padrão fordista-taylorista). O seu verdadeiro significado para o capital é a precarização do mercado e das condições de trabalho. Vista sob as cores do capitalismo hipertardio, a terceirização no Brasil só pode assumir, em seus contornos gerais, uma manifestação perversa. $\mathrm{O}$ tipo espúrio de terceirização passa, então, a ser a norma (e não a exceção)".

Deve-se lembrar de que "[...] apesar da extorsão da mais-valia relativa ter-se tornado o modo predominante de acumulação de capital no país, principalmente nas indústrias de ponta, a mais-valia absoluta não deixa de ser um importante componente histórico na produção capitalista no Brasil" (Alves, 1996:152).

O processo de terceirização em curso no país, em sua variante 'espúria' intensifica a extorsão de mais-valia absoluta e o comportamento da indústria calçadista francana diante dessa nova lógica do mercado, serve de exemplo pois, no ramo industrial, a subcontratação ou terceirização, como tem sido referenciada nos últimos tempos, é velha conhecida e convive com formas não especificamente capitalistas de exploração do trabalho como o trabalho em domicílio que pode, ou não, assumir características de trabalho familiar.

Analisar o processo de reestruturação produtiva no Brasil não é uma tarefa fácil bem como não é simples uma análise do que já foi produzido sobre o assunto. Tumolo (2001:3) que realizou uma revisão da bibliografia a esse respeito, abrangendo aproximadamente duas centenas de títulos de diferentes áreas do conhecimento, destaca que o que se constata é uma grande heterogeneidade nesse processo: “[...] Os resultados das pesquisas apontam que, sob diversos aspectos, o único consenso é o 'dissenso'. Em outras palavras, não é possível encontrar, pelo menos dentro dos parâmetros teóricos-metodológicos dos referidos estudiosos, nenhuma homogeneidade e nenhum padrão único ou mesmo determinante no que se refere a vários aspectos dos processos de trabalho: introdução de novas tecnologias, organização e gestão do trabalho, qualificação/desqualificação da força de trabalho etc. Tendo como base as pesquisas realizadas, é possível afirmar que a marca distinta do chamado processo de reestruturação produtiva no Brasil é a 'heterogeneidade generalizada', que ocorre não só entre as empresas, mas também no interior delas. Por esta razão parece difícil estabelecer comparações e conexões entre as diversas partes díspares desse mosaico". Por uma lado, se há consenso entre os autores por ele pesquisados de que o que distingue o processo de reestruturação produtiva em curso no país é a heterogeneidade em relação ao padrão tecnológico adotado, à organização e gestão do trabalho, não apenas entre setores da produção, empresas e no interior das próprias empresas, por outro lado, quanto aos trabalhadores, congruências são verificadas: "[...] No que diz respeito às relações de trabalho e às relações com as organizações sindicais, constata-se, ao contrário, uma 'congruência'. Praticamente todas as pesquisas que as tinham como objeto de investigação apontam a ocorrência da intensificação do ritmo de trabalho e da diminuição dos postos de trabalho e, ao mesmo tempo, um empenho das empresas no sentido de afastar e neutralizar a ação sindical, valendo-se de diversos mecanismos, desde a proposta de participação controlada dos trabalhadores até a perseguição e mesmo demissão sumária dos ativistas sindicais. Algumas pesquisas indicam, também, uma tendência de diminuição do preço do salário (Tumolo, 2001:3).

O processo de reestruturação produtiva em curso na indústria de calçados em Franca - SP enquadra-se nessas considerações.

\section{REESTRUTURAÇÃO PRODUTIVA E TERCEIRIZAÇÃO: SINÔNIMOS DE INTENSIFICAÇÃO E PRECARIZAÇÃO DO TRABALHO}

Uma das características da indústria de calçados masculinos de couro em Franca é o emprego intensivo de trabalho vivo. Esse ramo da indústria de calçados apresenta 
baixo índice de concentração de capital e adota processos de produção que, de modo geral, não fazem uso de tecnologias sofisticadas. Essa indústria absorve uma quantidade significativa de força de trabalho barata e, em boa medida, especializada, ou seja, detentora de conhecimentos, habilidades e destrezas manuais ainda imprescindíveis à produção do produto. Sua produção destina-se tanto ao mercado interno quanto ao externo e é realizada em parte nas indústrias, nas bancas ${ }^{3} \mathrm{e}$ parte a domicílio, e que envolve diferentes formas de relações de trabalho.

O processo de produção do calçado de couro envolve inúmeras operações que estão organizadas em torno de cinco etapas: modelagem, corte, costura - que pode ser manual ou à máquina (pesponto) -, montagem e acabamento. O número de operações realizadas em cada uma dessas etapas varia de acordo com o modelo de calçado a ser produzido, com o tipo de organização de trabalho adotada, com a tecnologia empregada e com o porte da empresa.

Nas indústrias de calçados em Franca estão empregados diretamente cerca de 17 mil operários. Grande número de trabalhadores presta serviço para essas indústrias e realizam parte da confecção do calçado fora de seus limites físicos. No entanto, dimensionar esse número não é tarefa fácil. Dados do Sindicato da Indústria de Calçados de Franca ${ }^{4}$ indicam a existência, na atualidade, de aproximadamente 2 mil prestadores de serviços (ou banqueiros) que realizam, sobretudo, serviços de pesponto e de costura manual. Em torno desses banqueiros orbita um número não quantificado de trabalhadores contratados para realizar o trabalho.

Entre os banqueiros, há diversidade de formas de relacionamento com as indústrias contratantes, no número de empregados contratados e nas instalações onde o trabalho é realizado: existe desde aquele pequeno banqueiro que realiza o trabalho de pesponto em sua casa com uma ou mais pessoas de sua família até o grande banqueiro que dispõe de instalações onde trabalham de 20 a 50 funcionários subcontratados.

Todavia, a despeito da precariedade dos dados disponíveis, essa realidade pode ser facilmente constatada com uma simples visita a bairros habitacionais periféricos de Franca, onde se pode observar, a amiúde, sua transformação em bairros industriais sem indústrias...

Esse processo de terceirização da produção, que se amplia em Franca a partir dos anos de 1990, já era prática difundida no setor. De forma geral, as empresas calçadistas francanas há muito terceirizavam sua produção quando o volume de encomendas ultrapassava sua capacidade produtiva. A partir de meados da década de 80 , essa prática deixa de ser exceção para tornar-se regra com o premente objetivo de reduzir custos. Esse fato explica em parte a grande redução de postos de trabalho nas indústrias de calçados de Franca. Na década compreendida entre os anos de 1986 a 1996 foram extintos 16 mil postos de trabalho no ramo industrial. A redução contínua no contingente da força de trabalho empregada pelo setor naquele período não foi conseqüência de uma redução significativa do volume da produção, que se manteve na média histórica de 27 milhões de pares/ano, à exceção dos anos de $1995 \mathrm{e}$ 1996, quando o volume produzido foi de 22 e $24,8 \mathrm{mi}-$ lhões de pares/ano, respectivamente. A redução no número de postos de trabalho nas indústrias foi acompanhada pelo crescimento do trabalho informal, precarizado, 'subcontratado', 'terceirizado' e do valor agregado ao produto.

Além do incremento das práticas de subcontratação por meio das bancas e do trabalho em domicílio, que desde esse período passa a ser ampliado crescentemente como forma de redução de custos nas empresas de grande porte e em parte das que se instalaram em Franca desde então, aumentou a preocupação do empresariado com a maior racionalização da produção no interior das unidades fabris. É, pois, no período compreendido entre os anos finais da década de 80 e início da década de 90, que um número maior de indústrias de calçados de Franca aderiu ao movimento de reestruturação produtiva e passou a realizar experiências de novas maneiras de se organizar a produção e o processo de trabalho, em boa medida inspiradas no "modelo japonês". Ressalte-se, aqui, que as modificações no planejamento e na organização da produção implementadas pelas indústrias de calçados de Franca vão-se dar sem grandes investimentos em máquinas e equipamentos que incorporam tecnologias baseadas na microeletrônica, com exceção de uma ou duas empresas que adquiriram equipamentos $\mathrm{CAD} / \mathrm{CAM}$ utilizados apenas na seção de modelagem.

Em algumas empresas francanas, as novas técnicas de gerenciamento da força de trabalho adotadas pressupunham o envolvimento dos trabalhadores no processo de reestruturação da produção mediante formação de grupos de discussão, em que o trabalhador era convidado a opinar, a dar sugestões a respeito da melhor forma de organizar a produção. Com isso, buscava-se contar com sua participação para diminuir o tempo de giro das mercadorias em produção, tornar mais ágil o 
processo de trabalho, melhorar a qualidade dos produtos e, conseqüentemente, obter aumentos de produtividade. Para tanto, além dos treinamentos, o envolvimento dos trabalhadores na implantação dessas mudanças passa a ser estimulado com a implantação de políticas de premiações individuais. Ocorre que a difusão dessas mudanças organizacionais entre as indústrias de calçados de Franca tem-se dado de forma lenta e não uniforme e, muitas das vezes, caem em desuso nas empresas que as adotam. Apesar de boa parte do empresariado do setor calçadista estar 'sintonizada' com o discurso modernizante, apregoando a imprescindibilidade da renovação das 'velhas' práticas de produção, administração e gerenciamento da força de trabalho - mudanças que garantiriam a permanência e a ampliação da competitividade de suas plantas industriais -, observase que a adoção desse discurso, na maioria dos casos, encontra-se em profundo contraste com a prática adotada pelas empresas, sobretudo no que se refere às condições e às relações de trabalho. 5

TABELA 1



\begin{tabular}{lcc}
\hline Ano & $\begin{array}{c}\text { Númerode } \\
\text { Trabalhadores }\end{array}$ & $\begin{array}{c}\text { ProduçãoMédia } \\
\text { Trabalhador/Ano(empares) }\end{array}$ \\
\hline 1984 & 36.000 & 888 \\
1994 & 25.000 & 1.240 \\
1997 & 17.000 & 1.705 \\
1999 & 17.000 & 1.941 \\
\hline
\end{tabular}

Fonte: Sindicato da Indústria de Calçados de Franca.

Se se levar em consideração que a indústria calçadista francana, em boa medida, não realizou investimentos de monta na adoção de maquinaria moderna e na ampliação e modernização de sua estrutura física, pode-se inferir que o aumento da produção média por trabalhador ao ano verificado no período de 1984 a 1999 (Tabela 1) deu-se mediante intensificação do trabalho nas fábricas ou nas bancas que a elas prestam serviços.

L.B., 43 anos, sapateiro, em seu depoimento confirma a tese anteriormente exposta:

"[...] o que a gente vê hoje nas fábricas é que tem menos trabalhador e um maior número de pares produzidos, caiu o número de trabalhadores e aumentou o número de pares. Aquele trabalhador que permaneceu na fábrica ficou com mais trabalho. Da forma como eles arrumaram o maquinário um trabalhador trabalha mais só que ganha a mesma coisa". ${ }^{6}$

Tal processo não se restringiu ao interior das fábricas e, como se ligado por vasos comunicantes, permeou para o conjunto das atividades realizadas fora de seus domínios, como as bancas que a elas prestam serviços e o trabalho realizado a domicílio. L.B. confirma:

"[...] no trabalho terceirizado a gente vê mais ainda a hora extra. Nas bancas, as pessoas chegam a trabalhar 18 horas por dia, porque se não consegue acabar a ficha (cota de trabalho a ser realizada no dia) ele tem que completar com a noite" ${ }^{6}$

M.S., 28 anos, costureira manual, afirmou:

"[...] eu trabalho costurando sapatos há mais de dez anos. Não é todo dia que tem serviço. Quando tem serviço eu pego nele às seis da manhã. Só paro para fazer o almoço e trabalho até as cinco da tarde. Costuro até 45 pares por dia. Quando eu não consigo durante o dia, trabalho à noite, até terminar a ficha. Nos fins de semana, meus filhos e meu marido me ajudam costurar". 6

Por um lado, no interior das unidades fabris, as principais mudanças observadas foram a redução de postos de trabalho, sobretudo daqueles relacionados às tarefas auxiliares nas diversas seções das fábricas; a utilização do trabalho em grupo ou células de produção que, pelo reagrupamento de tarefas antes realizadas individualmente, representou para o trabalhador apenas uma sobrecarga, uma superposição de tarefas, que passam a coexistir com a maior intensificação e controle do trabalho.

Por outro lado, o aumento da transferência de partes da produção para ser realizada fora das indústrias, nas bancas ou em domicílio, contribuiu para o agravamento das condições de trabalho em que a confecção do calçado é realizada, muitas vezes, em locais improvisados e inadequados e com jornadas de trabalho superiores a dez horas, sem folgas semanais. Quando as bancas são instaladas no domicílio do trabalhador, suas atividades invadem e perturbam o espaço destinado à família, quadro que é agravado pela quase impossibilidade da fiscalização desses ambientes de trabalho pelos organismos responsáveis pela higiene e segurança no trabalho.

O aumento do trabalho nas bancas e em domicílio puni ainda o trabalhador à medida que sobre ele recaem os efeitos da flutuação do mercado, visto que a necessidade desse tipo de trabalho pelas empresas é marcada pela sazonalidade. 


\section{CONSEQÜÊNCIAS DESSE PROCESSO PARA A SAÚDE DOS TRABALHADORES}

É líquido e certo que as condições de trabalho têm-se agravado tanto para os que permanecem formalmente empregados nas indústrias quanto para os que são empregados nas bancas e para os que realizam o trabalho em domicílio.

Ao transferirem para fora de seus muros o trabalho, as empresas também o fazem de forma eficiente, com os problemas, - desresponsabilizando-se de todo e qualquer direito social, além de transferir para o trabalhador a incumbência e a responsabilidade de zelar pelas próprias condições de higiene e segurança do trabalho, bem como dos que consigo vivem e trabalham. ${ }^{7}$

Nas visitas realizadas em domicílios de trabalhadores, pode-se observar que a invasão do espaço doméstico pelo trabalho assalariado (que pressupõe em muitos casos também a invasão de máquinas e equipamentos) além de subtrair do trabalhador e de sua família a privacidade do lar, coloca em risco a saúde de todos. O cheiro da cola, o pó do couro, equipamentos improvisados para o desenvolvimento de suas atividades, o ruído das máquinas que permanecem em funcionamento até mesmo em período noturno e em finais de semana são indicadores suficientes para afirmar que o aumento da informalização do setor, além de precarizar as relações de trabalho, agrava também as condições de trabalho, saúde e qualidade de vida dos trabalhadores e de seus familiares (é bom lembrar que as famílias são compostas também por idosos, pessoas doentes, neonatos e crianças de idades variadas).

Como se não bastasse, a invasão fabril do lar é também compartilhada pela vizinhança do trabalhador. Há inúmeros relatos, em Franca, de relações de amizade ou de vizinhança rompidas ou abaladas pela instalação de máquinas e equipamentos em espaços destinados à moradia. A instalação de balancins de $\operatorname{corte}^{8}$ no interior de residências, além de colocar em risco a saúde, tem provocado também irritação nos vizinhos, que compartilham o ruído provocado por esse equipamento. Há casos relatados, também, de rachaduras em paredes tanto do dono do equipamento quanto de seu vizinho. A instalação de espaços destinados ao desenvolvimento de atividades fabris em locais inadequados chegou a tal ponto que, recentemente, o sindicado dos trabalhadores recebeu denúncia de uma moradora da cidade pedindo providências, pois, seu vizinho que mora no andar de cima de um apartamento do CDHU instalou no local uma banca de pesponto, onde trabalha com a família até nos finais de semana.

As novas estratégias de planejamento da produção adotadas por parte das empresas do setor, que resultaram nas alterações das formas de divisão e organização do trabalho no interior das fábricas, impulsionaram a transferência de partes da produção para serem realizadas externamente e provocaram um quadro de agravamento e maior precarização das condições e das relações de trabalho.

No interior das fábricas, as principais mudanças observadas foram a redução de postos de trabalho, em especial daqueles relacionados a tarefas auxiliares nas diversas seções das fábricas; a utilização do trabalho em grupo ou células de produção, que, por meio do reagrupamento de tarefas antes realizadas individualmente originou o trabalhador polivalente ou multifuncional, à rotação de tarefas, mudanças essas que são apresentadas como estratégias modernas de se ajustar a produção à nova lógica capitalista, mas que, para o trabalhador representa, apenas, uma sobrecarga, uma superposição de tarefas, que passam a coexistir com maior intensificação e controle do trabalho.

O trabalho em grupo que, na maioria das vezes, pressupõe o pagamento pela produtividade do grupo, transferiu para os próprios trabalhadores a tarefa de controlar a si próprio e aos demais membros do próprio grupo. De forma geral, pode-se afirmar que essas mudanças provocaram maior controle e maior intensidade do trabalho, o que repercute na saúde física e mental dos trabalhadores. Não se pode deixar de observar que o desemprego, também, traz impactos na saúde do trabalhador, no entanto, essa é uma discussão que merece maior aprofundamento.

A repercussão das novas estratégias de planejamento da produção na saúde dos trabalhadores da indústria de calçados de Franca pode ser avaliada pelas recentes modificações tecnológicas adotadas pela Calçados Samello, empresa pioneira da reestruturação (desestruturação) produtiva do município.

Esta empresa, recentemente, realizou mudanças que implicaram substituição de postos de trabalho que eram realizados sentados, para postos de trabalho onde trabalha-se em pé. ${ }^{9}$ Há cerca de um ano iniciou-se a substituição das tradicionais máquinas de pesponto, em que o trabalhador realizava suas atividades sentado por outras em que o trabalho é realizado em pé. Na realidade, não houve investimento em maquinários novos, mais modernos, como se poderia supor. A empresa, na realidade, ape- 
nas adaptou suas antigas máquinas de costura de forma que seus empregados trabalhassem em pé. ${ }^{10}$

E.C., 51 anos, pespontador, declarou:

"[...] Hoje na fábrica é só máquina em pé. Tiraram todas as máquinas que a gente trabalhava sentado". ${ }^{11} \mathrm{O}$ trabalho em pé também foi estendido aos auxiliares de pesponto, que realizam os "trabalhos de mesa", ou seja, a preparação das peças que comporão o cabedal que, posteriormente receberão a costura. E continuou: "[...] As meninas que ajudam que faz os serviços de mesa é tudo em pé também". ${ }^{11}$

Em entrevistas realizadas com trabalhadores daquela indústria, verificou-se que a adoção desse novo "modelo" de trabalho não foi precedido de qualquer consulta prévia aos trabalhadores. É interessante notar que os depoimentos dos trabalhadores são coincidentes quando afirmam que não ocorreu um aumento na produtividade média e que a modificação efetuada trouxe somente sofrimento aos que ali trabalham. T.D., 49 anos, pespontador, comenta:

“[...] A máquina está colocada numa coluna para a gente trabalhar em pé. Embaixo tem uma espécie de um pedal alto com um pedalzinho no meio. Então o peso do corpo fica só numa perna e a outra a fica no pedal funcionando a máquina, controlando a máquina. Cansa dos dois jeitos, tanto a perna que fica para apoiar o corpo, como a outra que você usa no pedal... Você fica moído o dia inteiro, de baixo acima. ${ }^{11}$

E.C., 51 anos, pespontador, completa:

"[...] Eles falam [a chefia] que é pra gente trabalhar em pé que fica melhor para a coluna, mas eu acho que a coluna está piorando mais ainda, porque esforça mais trabalhar com uma perna só, o dia inteiro. O peso do corpo fica todinho em cima de uma perna só. Vamos supor, o cortador também trabalha em pé, mas eles ficam apoiados nas duas pernas, e eles têm mais movimento. Nós não, a gente se apóia em uma só perna o dia inteiro, e tem que ficar parado no mesmo lugar, aí não tem quem suporta. Tem um monte de amigo meu que saiu por causa disso daí, porque não estavam suportando essa vida. [...]". ${ }^{11}$

E ainda segundo seus relatos, quanto à má adaptação do maquinário, fez com que uma parcela dos trabalhadores fosse ainda mais punida:

“[...] A máquina tem a regulagem. Mas eu tenho um amigo que tem uma altura mais avançada. Ele não tá tendo como trabalhar. Ele me disse hoje que se mandassem ele embora para ele era a salvação. Porque ele não está tendo como trabalhar naquelas máquinas não. Igual eu que sou baixinho ... dá regulagem, igual você que tem uma altura média [1,60 m] também dá regulagem, mas os mais altos trabalham embodocados [com o tronco curvado]. Aí nesse caso é pior que trabalhar sentado, muito pior". 11

P.M., 36 anos, pespontadeira, declarou:

"Logo que eles colocaram estas máquinas em pé eu comecei a sentir dor. Eu não agüentava mais de dor nas pernas. Quando chegava em casa eu só queria cama. Então primeiro eu procurei o ambulatório da fábrica e o médico falou que era circulação. Aí eu fui no médico de circulação, não era. A dor vinha dos quadris e corria pras pernas aí ela [a médica] falou que era rins. Fiz exame e não deu nada. Aí ela falou: vou te encaminhar para o ortopedista. Aí eu fui, tirei chapa, eu não tenho nada na coluna, mas o nervo está inflamado. Inflamou o nervo ciático. Fiquei afastada quinze dias tomando remédios e voltei mesmo sem ter sarado, porque se eu ficasse afastada mais que quinze dias eu ia pro INSS, aí só Deus sabe quando eu ia receber meu salário". ${ }^{11}$

Os depoimentos desses trabalhadores, com apenas uma única questão que afeta seu cotidiano, trazem à luz elementos que elucidam a forma como o empresariado local trata a questão da saúde relacionada ao trabalho nesse ramo industrial.

É inegável que qualquer trabalho realizado em pé, em uma mesma postura, durante toda a jornada, trará problemas de saúde. No caso dos pespontadores dessa indústria, existe o agravante do trabalhador ter de ficar durante horas em uma mesma posição com o peso do corpo distribuído em apenas uma das pernas, pois a outra deve ficar livre para acionar os mecanismos que ativam a máquina. Minayo-Gomez e Thedim-Costa (1997:24) em uma análise do trabalho realizado em condições inadequadas afirmam que "[...] a evidência dos efeitos do trabalho em condições adversas é de tal ordem que extrapola os limites do conhecimento legitimado como científico e ganha espaço no âmbito do senso comum. É uma relação dada e inquestionável. Faz parte da vivência de trabalhadores, vítimas de doenças e acidentes, mesmo quando não obtêm êxito em comprovar sua origem na atividade exercida. Reconhecem-na suas famílias, onde tais situações repercutem, em alguns casos, de forma drástica, e os compa- 
nheiros que com eles compartilham esse quadro de desrespeito e omissão [...]".

O depoimento de P.M. traduz, de forma simples, o exposto:

"Tem uma pespontadeira lá que trabalhava do meu lado. Durante todo o tempo do teste [período de experiência] ela trabalhou rezando. Ela me falou que não agüentava de dor nas pernas, mas ela precisava do emprego. Então tinha que se apegar na oração para não lembrar da dor". ${ }^{11}$

Um outro aspecto importante, revelado pela trabalhadora, é o da dificuldade de diagnóstico e o não-estabelecimento, pelo médico do ambulatório da empresa, do nexo causal existente entre a queixa relatada pelo trabalhador e o trabalho realizado por ele. À ineficiência do atendimento médico oferecido pelo empresariado superpõemse às deficiências dos serviços prestados pela previdência social que, por não apresentarem um viés investigativo, com certeza deixarão sem causa e, por conseguinte, sem punição a dor e o sofrimento dos trabalhadores que, de uma forma ou de outra, pagam por esses serviços.

Essa "simples" mudança no processo produtivo implantada na indústria francana foi drástica o suficiente para que um número crescente de trabalhadores tenha pedido sua demissão em uma época de crise de emprego, por serem incapazes de suportar as dores provocadas pela jornada de trabalho.

E.C., 51 anos, em seu depoimento, disse:

"[...] Depois que eles instalaram [as máquinas de pespontar em pé], saiu muita gente. Teve mulher que pediu demissão: não conseguia mais ficar lá em pé. E isto tanto faz pessoa de idade quanto pessoa mais nova. Ficou pesado pra todo mundo. Eu tenho uma amiga minha que estes dias mesmo ela ficou afastada por causa disto". ${ }^{11}$

Alguns depoimentos faz supor, entretanto, que os pedidos de demissão sejam acompanhados de pressão, por parte de gerentes ou seus prepostos, sobre os que ousaram reclamar das desumanas condições de trabalho. Veja o que disse A.E., 35 anos, pespontadeira:

“[...] teve gente que saiu. Um colega meu pediu para ser mandado embora porque ele não se adaptou em ficar [trabalhar] em pé, ele estava sentindo muitas dores nas pernas então preferiu sair. Ele foi falar para eles [para a gerência] que não agüentava trabalhar em pé e eles falaram: 'a norma da empresa é essa aí, se você não se adapta tem que ser mandado embora'. Aí ele mandou embora. Agora ele está trabalhando sentado, em casa. Ele e a mulher dele". ${ }^{11}$

Ocorrem casos também de punições aplicadas em trabalhadores que "ousam" buscar tratamento médico e afastamentos para cuidar da saúde, conforme continuou A.E. em seu relato:

"[...] E ainda tem aquele negócio... Se você fica afastado aí, no outro dia que você volta você vai ter que ir lá na sala - a gente fala: vai lá na salinha [onde fica o gerente]. Você tem que ir falar porque foi ao médico, porque ficou afastado. Você tem que ir lá para dar explicação para ele [o gerente]. Então, além de você ter que ir ao médico, você tem que escutar, leva pito! Eu acho que eles fazem isto pra pessoa não ir ao médico, pra ficar com medo: Ah! Se eu for ao médico depois vou ter que ir à salinha $[\ldots]$ ". ${ }^{11}$

É marcante o contraste entre a diversificação das formas de superexploração e dilapidação da força de trabalho e o discurso da empresa sobre o processo de reestruturação produtiva por ela implantada, que pressupunha o envolvimento participativo de seus funcionários: "Estamos tratando a área humana com o mesmo carinho com que se lapida um diamante" (Samello, 1990).

\section{CONSIDERAÇÕES FINAIS}

O debate hoje acerca da saúde do trabalhador remete ao quadro das transformações que estão em curso no mundo do trabalho, o que possibilita compreender como estão configurando as novas formas de intensificação da exploração da força de trabalho, que é uma das principais características do novo padrão de acumulação do capital. Sua objetivação tem-se dado, quer por meio da adoção de novas tecnologias, da utilização de novas formas de organização da produção e do trabalho ou de mudanças nas próprias relações de trabalho que implicam contratos precários, na subcontratação, no trabalho em domicílio, no aumento desmedido da jornada de trabalho e, até mesmo, na exploração criminosa do trabalho infantil. Gerando um quadro de violência no trabalho, que "[...] em nossa sociedade vem assumindo contornos epidêmicos [...]" (Navarro et al., 2001), como bem demonstra a realidade dos trabalhadores da indústria de calçados de Franca, objeto de minhas pesquisas.

O enfrentamento dessa questão não pode ser pensado apenas no plano da fiscalização dos ambientes de trabalho, de políticas voltadas para a saúde do trabalhador, ainda 
que não se possa prescindir delas, e há muito ainda a ser feito nessas instâncias que pode contribuir para a melhoria dos ambientes de trabalho e saúde dos trabalhadores. Devese salientar que, de maneira mais ampla, o tratamento das questões que envolvem os destinos da classe trabalhadora não pode se dar sem que, tanto na teoria quanto na prática social, se reafirme a centralidade do trabalho.

Antunes (1999:204-205), contrapondo-se aos que afirmam o fim da centralidade do trabalho, afirma que "[...] o que se vê [hoje] não é o fim do trabalho e sim a retomada de níveis explosivos de exploração do trabalho, de intensificação do tempo e do ritmo de trabalho [...] e é exatamente isso que vem ocorrendo em praticamente todas as partes: uma maior intensidade, uma maior exploração de força humana que trabalha".

Ainda segundo Antunes (1999:244), o grande desafio hoje é "[...] olhar para uma sociedade que vá além do capital, mas que tem que dar respostas imediatas para a barbárie que assola a vida cotidiana do ser social que trabalha".

Toda essa complexidade deve ser compreendida para que se possa evidenciar, cada vez mais, o vínculo entre a saúde e o trabalho nesse momento de substanciais mutações no mundo do trabalho para, valendo-se dessa compreensão, possa-se reafirmar o compromisso com uma sociedade na qual os homens sejam tratados como homens, como seres humanos que são.

\section{NOTAS}

1. Franca, localizada na região nordeste do Estado de São Paulo, dista aproximadamente $400 \mathrm{~km}$ da capital do Estado e é o maior pólo produtor e exportador de calçados masculinos de couro do Brasil. Este segmento industrial consolidou-se em Franca na década de 70 quando à demanda crescente do mercado interno, estimulada pelo processo de industrialização e urbanização vivido no país, somou-se a expansão da produção destinada à exportação.

2. O elevado número de acidentes e doenças provocados pelo trabalho no país é a prova mais emblemática desse fato. "O número de acidentes de trabalho declarados por trabalhadores segurados da Previdência Social situa-se hoje, no Brasil, entre 400 e 500 mil ao ano. Aproximadamente 15 pessoas em cada 1.000 segurados sofrem acidentes no exercício de suas atividades laborais anuais. É uma proporção enorme. Um tributo muito forte pesa sobre os corpos dos trabalhadores. Não se trata apenas do cansaço cotidiano, resultante da atividade física. É a laceração da carne, o ofuscar das mentes e a perturbação dos espíritos de homens e mulheres que são pagos como tributo pela sobrevivência" (Dal Rosso et. al., 2001:95).

3. As bancas são unidades produtivas (oficinas de trabalho) que prestam serviços à indústria. No que se refere ao seu porte, há as que contam com apenas dois ou três trabalhadores de uma mesma família, as de porte médio que empregam cerca de 15 ou 20 trabalhadores e as grandes bancas, que podem recrutar uma centena de trabalhadores. De forma geral, as bancas são especializadas em realizar determinadas tarefas que fazem parte do núcleo principal da confecção do calçado, como o corte, o pesponto, etc. A grande parte dessas oficinas de trabalho são instaladas em locais improvisados e/ou adaptados da moradia do trabalhador, como uma garagem, alpendre, quintal ou varanda da casa ou ainda em salas e galpões alugados. É comum tanto às pequenas "bancas" montadas nas moradias, como às maiores, que possuem prédio próprio, a precariedade do ambiente de trabalho, que pode ser auferida pela pouca iluminação, pela falta de ventilação, pelo não uso de equipamentos de segurança, pela exposição a solventes e pelo ruído ensurdecedor provocado pelas máquinas.

4. Informação obtida no site "Fiesp/Ciesp on line". A mesma fonte ainda informa que em Franca existem "360 fabricantes de calçados, $70 \%$ micro e pequenos; $20 \%$ de médio porte; e $10 \%$ correspondem a empresas de grande porte [...]. Juntam-se a esse universo cerca de 200 fornecedores de insumos especializados; 20 fabricantes de equipamentos; oito agentes exportadores; e 2000 prestadores de serviços". Disponível em: <www.fiesp.org.br>. Acesso em: 17 set. 2002.

5. "O setor calçadista é um ramo industrial relativamente resistente à mudança. Os empresários, de modo geral, assumem postura conservadora que os faz hesitar e postergar a implementação de alterações significativas em suas fábricas" (Costa, 1995:96).

6. Entrevista concedida em 27/04/2001.

7. "Como freqüentemente as doenças originadas no trabalho são percebidas em estágios avançados até porque muitas delas, em suas fases iniciais, apresentam sintomas comuns a outras patologias, torna-se difícil, sob essa ótica, identificar os processos que as geraram, bem mais amplos que a mera exposição a um agente exclusivo. A rotatividade da mão-de-obra, sobretudo quando se intensifica a terceirização, representa um obstáculo a mais nesse sentido" (Minayo-Gomez; ThedimCosta, 1997).

8. Os balancins de corte são equipamentos hidráulicos pesados que necessitam, para seu correto funcionamento, de instalações adequadas, como contrapisos de concreto reforçado, que são caras para um trabalhador terceirizado.

9. De acordo com depoimentos de técnicos do Ministério do Trabalho reunidos em 18/09/2002, em Birigui (SP) - principal pólo produtor de calçados infantis do país -, para discutir questões referentes à saúde dos trabalhadores com as entidades sindicais e empresários das indústrias de calçados, tal prática é recente nos pólos calçadistas do Estado de São Paulo. Nessa reunião, Paulo Antonio Barros Oliveira, coordenador do setor de ergonomia do Ministério do Trabalho, afirmou que trabalho em pé no pesponto e nos trabalhos de mesa tiveram início a cerca de cinco anos nas indústrias de calçados do pólo calçadista do Rio Grande do Sul, onde a prática é bastante disseminada. Em Birigui, a prática de manter os funcionários trabalhando em pé data de 1999 e se originou na visita de empresários locais a indústrias de calçados instaladas no Rio Grande do Sul, de onde "importaram" a idéia: "[...] de um dia para o outro [os trabalhadores] foram surpreendidos com a retirada de seus assentos dos postos de trabalho e, ao adentrarem às fábricas, verificaram que as mesas nas quais executavam suas atividades haviam sido erguidas e que, daquele momento em diante, teriam que realizar suas funções em pé." (Sindicato dos Trabalhadores nas Indústrias de Calçados de Birigui, s.d.p., mimeo.). Ainda segundo os técnicos do Ministério do Trabalho, a prática de obrigar os trabalhadores da seção de pesponto e dos trabalhos de mesa a exercerem suas atividades em pé, está também disseminada nas indústrias calçadistas instaladas no nordeste do país.

10. Essas informações foram prestadas pelo Sindicato dos Sapateiros que vem recebendo constantes denúncias de trabalhadores. Essas denúncias são coincidentes com os depoimentos de trabalhadores dessa empresa por mim entrevistados.

O trabalho em pé, na forma como proposto pelas empresas calçadistas francanas, fere a norma regulamentadora NR 17 - Ergonomia (117.0007) do Ministério do Trabalho e do Emprego que afirma, textualmente, em seu item 17.3.1. "Sempre que o trabalho puder ser executado na posição sentada, o posto de trabalho deve ser planejado ou adaptado para esta posição (117.006-6/ I1)." 
11. Entrevista concedida pelo funcionário da Calçados Samello em $16 / 09 / 2002$

\section{REFERÊNCIAS BIBLIOGRÁFICAS}

ALVES, G. Nova ofensiva do capital, crise do sindicalismo e as perspectivas do trabalho - o Brasil nos anos noventa. In: TEIXEIRA, F.J.S.; OLIVEIRA, M.A. de (Orgs.). Neoliberalismo e reestruturação produtiva: as novas determinações no mundo do trabalho. São Paulo: Cortez: Universidade Estadual do Ceará, 1996.

ANTUNES, R. Os sentidos do trabalho: ensaio sobre a afirmação e a negação do trabalho. São Paulo: Boitempo, 1999.

BRAVERMAN, H. Trabalho e capital monopolista: a degradação do trabalho no século XX. Rio de Janeiro: Guanabara, 1987.

COSTA, B.M. da. Os impactos do progresso técnico sobre o emprego, a qualificação e as relações de trabalho. Dissertação (Mestrado) - Instituto de Filosofia e Ciências Humanas da Universidade Federal do Rio Grande do Sul, Porto Alegre, 1995.

COSTA, M.R. da. As vítimas do capital: os acidentados do trabalho. Rio de Janeiro: Achiamé, 1981.

DAL ROSSO, S.; BARBOSA, M.L.; FERNANDES FILHO, H.P. Intensidade do trabalho e acidentes. In: SILVA, J.F.; LIMA, R.B.; ROSSO, S.D. (Orgs.). Violência e trabalho no Brasil. Goiânia: UFG; Brasília: MNDH, 2001.

DIEESE. O processo de terceirização no Brasil. Seminários \& Eventos. São Paulo: n.1, p.34-35, set. 1994.

FARIA, A. de. Terceirização: um desafio para o movimento sindical. In: MARTINS, H. de S.; RAMALHO, J. R. (Orgs.). Terceirização: diversidade e negociação no mundo de trabalho. São Paulo: Hucitec, Cedi/Nets, 1994
IANNI, O. Origens agrárias do Estado brasileiro. São Paulo: Brasiliense, 1984.

MARX, K. O capital. São Paulo: Ciências Humanas, 1978, livro I, cap.VI (inédito).

MINAYO-GOMEZ, C.; THEDIM-COSTA, S.M.da F. A construção do campo da saúde do trabalhador: percurso e dilemas. Cadernos de Saúde Pública, Rio de Janeiro, v.13 (supl. 2), p.21-32, 1997.

NAVARRO, V.L. A produção de calçados de couro em Franca (SP): a reestruturação produtiva e seus impactos sobre o trabalho. Tese (Doutorado) - Faculdade de Ciências e Letras da Unesp, Araraquara, 1998.

NAVARRO, V.L.; ALESSI, N.P.; LIMA, M. da G. A violência do trabalhador no contexto da reestruturação produtiva no Brasil. In: SILVA, J.F.; LIMA, R.B.; Dal ROSSO, S. (Orgs.). Violência e trabalho no Brasil. Goiânia: UFG; Brasília: MNDH, 2001.

SAMELLO em sucessão: um legado com muito carisma. In: Lançamento. [S.1.]: Grupo Editorial Sinos, n.43, jan./fev. 1990.

SANTOS, J.V.T. dos. Colonos do vinho: estudo sobre a subordinação do trabalho camponês ao capital. São Paulo: Hucitec, 1984.

TUMOLO, P.S. Reestruturação produtiva no Brasil: um balanço crítico introdutório da produção bibliográfica. Educação e Sociedade, Campinas, v.22, n.77, dez. 2001,p.1-20. Disponível em: <http://www.scielo.br>. Acesso em: 10 set. 2002.

Vera Lucia Navarro: Professora do Departamento de Psicologia e Educação da Faculdade de Filosofia, Ciências e Letras de Ribeirão Preto-USP(vnavarro@usp.br). 